\title{
Factors Affecting the Behavioral Intention to Use Standalone Electronic Personal Health Record Applications by Adults in Egypt
}

\author{
Ashraf Elsafty $^{1}$, Islam M. Elbouseery ${ }^{1} \&$ Ashraf Shaarawy ${ }^{2}$ \\ ${ }^{1}$ Adjunct Assistant Professor, Maastricht School of Management, Cairo Outreach, Egypt \\ ${ }^{1}$ Health IT Consultant, Cairo, Egypt \\ ${ }^{2}$ Senior Researcher, Dr. Ashraf Elsafty Consulting, Giza, Egypt \\ Correspondence: Ashraf Elsafty, Adjunct Assistant Professor, Maastricht School of Management, Cairo Outreach, \\ Egypt. ORCID ID: https://orcid.org/0000-0002-9377-7286. E-mail: ashraf@ashrafelsafty.com
}

Received: October 29, 2020

Accepted: November 19, 2020

Online Published: November 23, 2020

doi:10.11114/bms.v6i4.5066

URL: https://doi.org/10.11114/bms.v6i4.5066

\begin{abstract}
Standalone electronic personal health record can be a useful tool that enables individuals to store, arrange and share their health information easily and they can build a history of their health timeline which is crucial for raising healthcare quality and better self-management, the adoption rate of these applications has been identified in several countries to be low and slowly progressing.

Although there are some applications of standalone ePHR available in the market for usage free of charge but it's almost not adopted at all, this study will investigate some of the factors that might affect the adoption of ePHR technology by adults in Egypt and provide business professionals a better picture for what can motivate or hinder the adoption process to achieve better adoption rates and eliminate the barriers.

In order to ensure a comprehensive contextual analysis, researchers analyzed the research in hand with the perspective of the proposed contextual framework, the Nine Elements Framework/Model (Elsafty, 2018) that analyzes social studies research in general, and business/management reseaerches as well.

Using the nine elements framework, the authors used it to discover the underlying factors that are causing the problems faced by the research in hand, and resulted in the coming contextual analysis defining the research scope and focus, which in the case of this paper is on Perceived usefulness and perceived ease of use were adapted from TAM that was initially developed by Fred Davis (1989) and they proved to have a high predictive power of behavioral intention in CHI context, The extensions of TAM including UTAUT \& UTAUT2 seems to be irrelevant to this research context since UTAUT is more oriented towards the organizational context (Venkatesh et al., 2012) and UTAUT2 added factors, Price value seems to be irrelevant in this research context as we are already studying platforms that are provided free of charge, Hedonic motivation maybe irrelevant to this context as healthcare related service is mostly associated with seriousness and urgency, also testing unimplemented platforms that are not yet adopted makes from the habit unrealistic experience that may be inaccurate to measure.

Since other several researches recommended extending these factors with other additional factors to make it more relevant to the healthcare consumer context (Kim \& Park, 2012), these factors may include health-related factors, technology-related factors and personal-related factors. Findings in this research revealed that adoption rate in Egypt is still very low and high demand for this service which makes this research is significant as it's trying to find out the reasons behind this gap, perceived usefulness, perceived ease of use, (privacy and security), eHealth literacy, personalization and awareness had a significant impact on behavioral intention to use standalone ePHR applications. Personalization was found to have the strongest effect on behavioral intention followed by perceived usefulness. Health status was found to have an insignificant effect on behavioral intention which indicates the interest of people with different health statuses in standalone ePHR.
\end{abstract}

Keywords: TAM, Consumer Health Informatics, patient engagement, personal health record, Egypt

\section{Introduction}

Healthcare IT has become one of the most important aspects to improve healthcare service quality. The patient 
engagement through an electronic personal health record can aid in achieving the Continuum of care and enabling healthcare service consumers to actively participate in the decision-making process, maintain health wellness and disease management (Demiris, 2016). Conducting the research contextual analysis using the None Elements Framework/Model (Elsafty, 2018), as an anatomy model to closely study organizations and different contextual cases before attempting to solve any noticeable problems. On the way to contextual analysis of the research, Elsafty (2018, $2019,2020)$ provided a holistic framework to analyze the case using nine elements covering the whole ecosystem of educational organization(s) and all related stakeholders, including suppliers, distributors, customers, competitors, government agencies, and so on - involved in the delivery of educational outcomes, and related service through both competition and cooperation. The nine elements framework has been used in several research papers (Elsafty, Elsayed, \& Shaaban, 2020; Elsafty \& AlNawaly, 2020; Elsafty \& Ragheb, 2020; Elsafty \& Abadir \& Sharawy, 2020).

Despite the enormous benefits of ePHR systems but its adoption has been low in several countries including developing and developed countries (Ford et al., 2016; Katehakis et al., 2018), also its dispersion rate is slowly growing (Ford et al., 2016; Katehakis et al., 2018), many studies discussed several factors that can affect the adoption of using such systems and it was found that many factors can affect the adoption process (Abd-alrazaq et al., 2019a). these factors were either motivating or hindering the adoption process, knowing the true predictors of behavioral intention to use these systems is crucial for achieving success in making ePHR systems more usable and have a widespread in different countries.

Egypt is considered one of the vital countries in the Middle East and it is one of the most populous countries in the region (Worldpopulationreview, 2019). Egypt witnesses a phase of development in health sector according to the sustainable development vision 2030 (WHO, 2017), Egypt plans for the involvement of mobile healthcare applications into the healthcare system in the upcoming period (MCIT, 2019). Adoption of ePHR has many challenges that have been defined over several studies and interoperability was one of these important challenges, on the other side there are other solutions available in the market by which the consumers can completely own and manage their data without need of interoperability at the moment like standalone ePHR. People can manually enter their data or capture, import and securely share documents with these platforms and they can use it primarily as a data repository that can be accessible and available everywhere overcoming the portability challenges of papers. In Egypt, there is almost $53.5 \%$ internet penetration projected in 2019 (Statista, 2019) and around 39 million Facebook profile of the total population, while 36\% of total population use mobile social networks including messaging and information exchange platforms like Facebook, Whatsapp, Youtube and many others (Reda, 2018), Egyptians also showed interest in using mobile health services (Amer,2012; Mansour 2017), the rising potential of health information exchange through these platforms is possible and can have a preference as they are widely used and adopted by users, However exchanging health information over social networks also has its risks of a disorganized and scattered information plus other privacy and security breaches that might happen so finding a new way to exchange health information between consumers and care providers is waving with the urgency in the near future, As stated by Badran (2019) that Egypt has $80 \%$ demand for electronic health record by consumers that means Egyptians will accept such technology once it's available in the market (Badran, 2019), despite the huge benefits of ePHR and its impact on several levels starting with individual level to the organizational and governmental level, but (Mansour, 2018) concluded that the adoption of using a personal health record in Egypt is still very low compared to other developed countries like Australia, Canada and U.S.A. Mansour (2018) found that almost zero percent of his sample was never using or hearing about standalone ePHR. Thus, this research represents a study of the determinant motivators and barriers affecting the behavioral intention to use a standalone electronic personal health record from the adult consumer perspective in Egypt.

\section{Adoption of PHR in Egypt by consumers}

So far, just one study found that investigated the perception of Egyptian patients of using personal health record has been conducted by Essam Mansour in 2018 to study how will Egyptian patients will perceive the potential benefits and usability of PHR and also determine the barriers that can inhibit the successful adoption (Mansour, 2018).

Mansour picked up a random sample of Egyptian patients using government hospitals without representing any specific category. He surveyed 112 patients ranging from 25 to more than 61 years old. About $40 \%$ of this sample was using PHR while $60 \%$ are still not using it. $80 \%$ of the people using PHR are using it through the facilities where they get the healthcare service like hospitals or clinics. The usage of independent electronic platforms like standalone ePHR was almost zero in this study. It was the most relevant case that can give very near indicators to the context of the standalone ePHR, however there might be some discrepancies between them because of the difference of the product clarified in this research or even other limitations in Mansour research (Mansour, 2018).

The study found that PHR users were very interested in medical reports, laboratory results, X-Ray reports and observations from nurses and doctors. Perceived usefulness and perceived ease of use showed significance in PHR users. Demographic factors like age and gender were insignificant predicting the PHR usage or even the relationship with 
access to health records, the study validated that PHR can enhance patient-physician relationship and trust as it was the perception of $73.4 \%$ of PHR users. $64.4 \%$ of PHR users perceived that PHR helps them to better understand their medical condition, this sample showed a good perception of PHR users about the potential benefits and how useful the system is and also the ease of using it was a motivator to the intention to use this new technology regardless age or gender as it has a minor effect (Mansour, 2018). This result ensure that perceived ease of use and perceived usefulness can be significant motivators for the intention to use a standalone ePHR system.

Violation of privacy also was one of the significant barriers to use PHR as almost $93 \%$ of users perceived this factor as a significant barrier to their usage (Mansour, 2018), this indicates the importance of this factor and its effectiveness in the Egyptian context.

The study also concluded that people with poorer socioeconomic levels are less likely to use PHR, that conclusion might affect sample selection in the case of standalone ePHR that sample will be from urban areas like urban cities where we can find a relevant population to pick a sample of, in urban cities, people have more access to better healthcare services with higher quality and a lot of people are using the digital technology and have ICT experience. Mansour was trying to make a comprehensive outlook of the PHR usage that included users and non-users of PHR but the main focus was on the people using PHR, Mansour stated that lack of awareness, lack of interest and time consuming have effect in the nonuse of PHR and described that adoption of PHR in Egypt by the vast majority is still very low. Mansour describes Egypt by being not yet prepared for the implementation of PHR as many provinces in Egypt still not using eHealth technologies and regulations need to be adapted for eHealth settings, that means that Egyptians in urban especially central cities like Cairo and Alexandria are most likely to use PHR than others smaller cities and towns or in rural areas with poorer socioeconomic levels (Mansour, 2018).

A lot of PHR users in this study perceived using PHR as useful and easy to use which indicates that usefulness and ease of use have a considerable effect on their intention to use PHR.

The study has some limitations like handling a small sample size so the represented results cannot be generalized outside the environment of research and it was mainly focusing on the patients that are currently using PHR which is not the case in this research that focuses on the people who are not using PHR, the study also didn't show much relationships between patient demographics and the use and non-use of PHR or the effect on other variables. Although the study has shown a snapshot of the PHR status and its user characteristics but it's missing the identification of other factors that affect the intention to use PHR. The case of Mansour was mainly focused on the tethered ePHR. However tethered ePHR may be different from other types of ePHR like Standalone or integrated ePHR as standalone and integrated ePHR can support different functions that tethered ePHR cannot support, so the factors that affect the adoption of each type of ePHR can be different (Abd-Alrazaq et al., 2019a).

\section{Literature Review}

The importance of ePHR systems has been growing over years while it was proving huge benefits for all healthcare stakeholders in literature review chapter, ePHR applications can be a source of health information that promotes better health outcomes (Tang et al., 2006), although ePHR applications have multiple benefits to all healthcare stakeholders but its adoption rate is still very low and progressing slowly by time (Ford et al., 2016).

Several studies worldwide have studied the factors that influence the acceptance of ePHR and detected more than 50 factors that can affect adoption intention of these services which reflect the complexity of this context (Abd-alrazaq et al., 2019a).

Egypt is one of the promising countries in the middle east and considered one of the most populous countries in this region (Worldpopulationreview, 2019), Egypt sustainable development vision 2030 is considering health sector a one of the important topics that will witness a development in the digital era (Who, 2017) and will be interested in applying mobile applications that provide health information and health services, ePHR would be a suitable topic to investigate since the health sector in Egypt either on the public or private levels are interested in digital health services, however the implementation of such services might face some challenges and barriers, there are already some applications in the market that provide a standalone ePHR services and available for free in the Egyptian market but in a previous study in Egypt by Essam Mansour, (2018) concluded that the adoption and usage of personal health record at all of its types in Egypt is still very low by the vast majority of Egyptian people. This result was a big motive to investigate the factors that can motivate Egyptian adults to adopt such systems and the barriers that needs to be clearly addressed and considered by standalone ePHR system providers and business professionals.

\section{Standalone ePHR}

A standalone ePHR can be a portal on the internet, smartphone application or either on a personal computer in which patients are responsible for the entry of all health information they get from different EHRs or even a patient-generated 
health data (PGHD). Standalone ePHR is not hosted by any organization or co-payers but it may connect to healthcare providers' EHR systems or co-payers' system that allows the flow of data into and from the ePHR, one of the advantages of this type is users are the owners and controllers of their own health data (Raisinghani \& Young, 2008; Fuji et al., 2012).

\section{Benefits of Standalone ePHR}

For individuals, It helps individuals as a first step to transform all paper health record to a digital format and easily organize these record, Availability and Portability of health information has become a better way to easily access health records anywhere which can be tremendously beneficial to individuals specifically to people who are used to travelling a lot or migrating from a country to another. It can enhance the communication between patients and physicians, it helps patients in self-management and disease tracking for chronic patients, it also helps women in tracking their health status during pregnancy period, it enables individuals and patients to participate in the decision making process and elevates ownership of their own health decisions, it can save cost and time for patients by avoiding repeated medical procedures like lab tests and radiology exams (AHIMA, 2005; Winkelman et al., 2005; Tang et al., 2006; Kaelber \& Pan, 2008; Roehrs et al., 2017; Alyami \& Song, 2016; Andrikopoulou et al., 2018 ).

\section{Theories and models used in studying adoption of ePHR}

It was found that several theories and models have been developed to study the behavioral intention starting from 1962 until 2015, many researchers tried to study technology acceptance in several aspects like DOI theory, TRA, TPB, TAM, UTAUT, UTAUT2 and others were interested in health behavior like HBM, PMT and others were interested in studying technology acceptance in health information like HITAM, PHRAM and CHISAM, the researcher found that extended TAM models were widely used and it was able to give a better explanation of health information technology acceptance because of the complexity of health context that needs other variables to be added to become more context-related, the researcher explored in details factors that might influence behavioral intention to use ePHR and health information technologies from several countries trying to identify what are the most common and important factors that might be also relevant to the Egyptian context.

Figure 1 shows the technology acceptance model that was proposed by Fred David in 1989 and its constructs

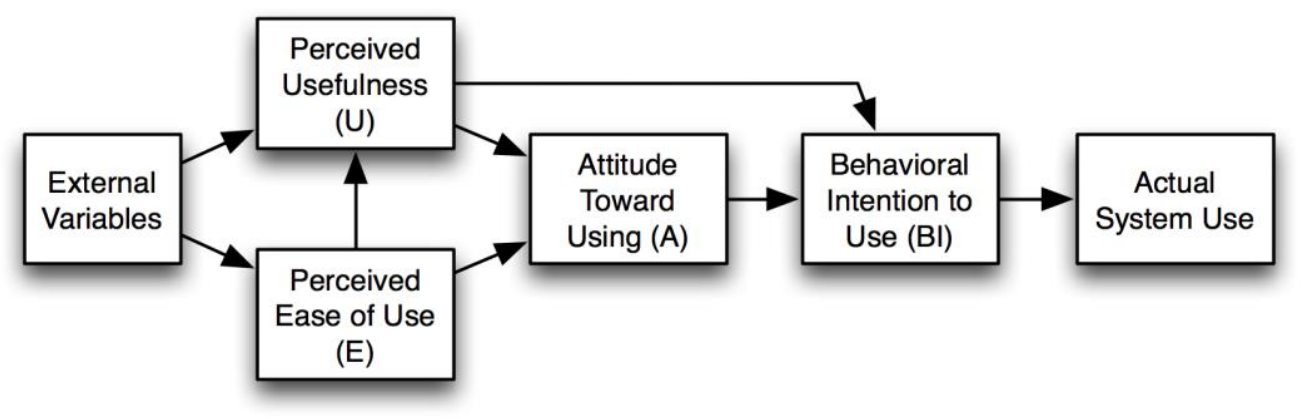

Figure 1. Technology Acceptance Model

Source: (Davis, 1989)

Figure 2 shows the UTAUT theory which was developed from TAM by Venkatesh in 2003. This theory added to TAM other constructs like social influence and facilitating conditions with other moderating variables like gender, age, experience and voluntariness of use. 


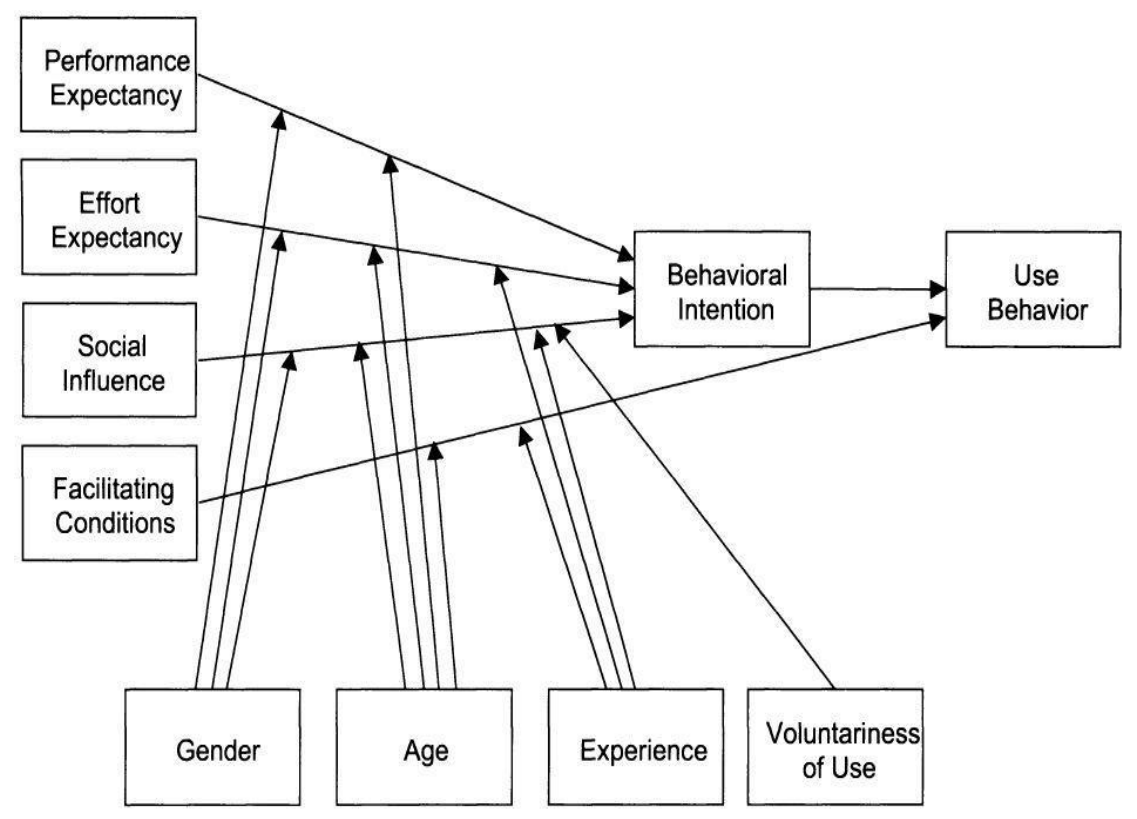

Figure 2. Unified Theory of Acceptance and Use of Technology (UTAUT)

Source: (Venkatesh et al., 2003)

Figure 3 shows UTAUT2 model which was developed from UTAUT in 2012 with added constructs of hedonic motivation, price value and habit.

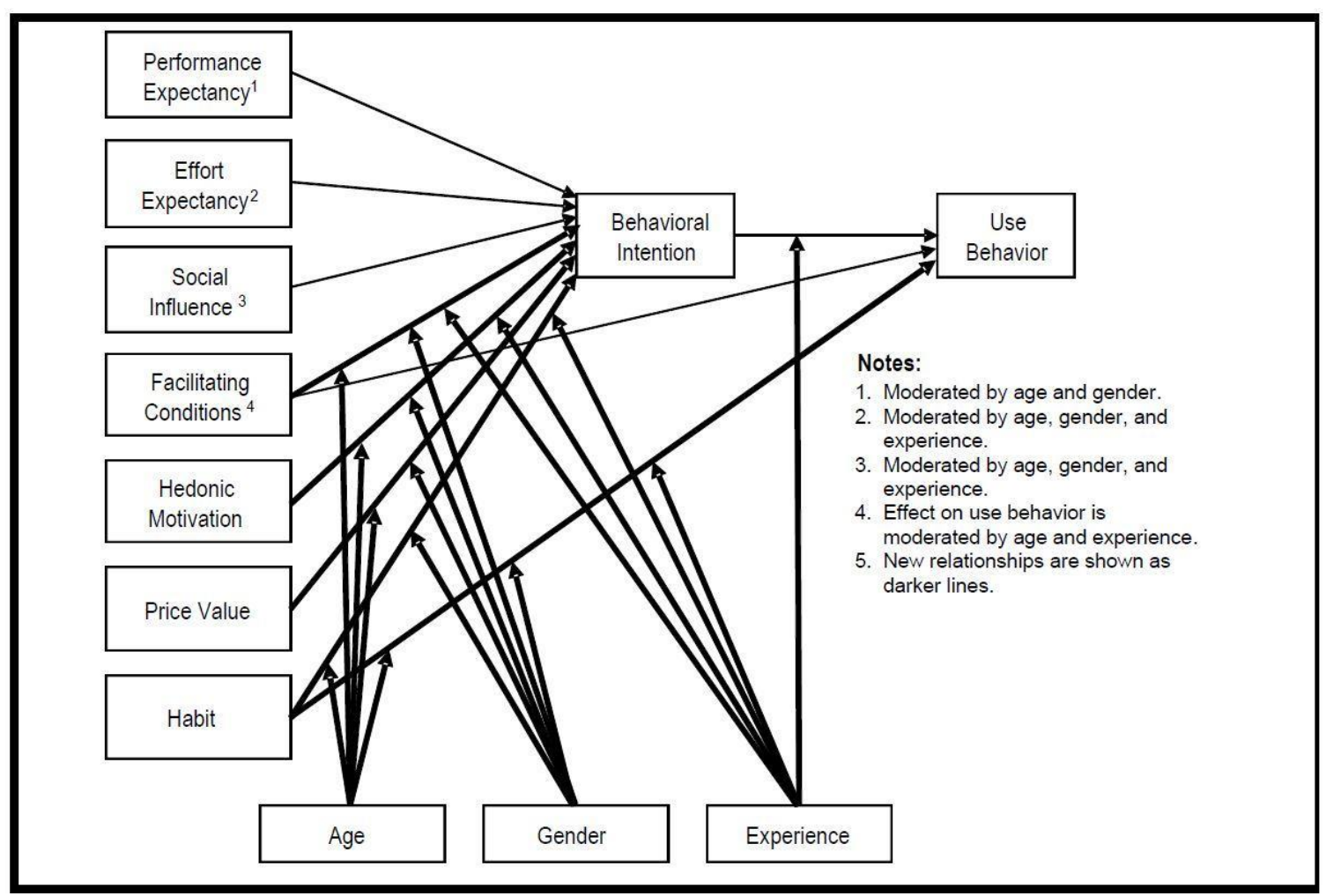

Figure 3. Extended Unified Theory of Acceptance and Use of Technology (UTAUT2)

Source: (Venkatesh et al., 2012) 
Figure 4 represents the understanding of the researcher about theories and models that have been mentioned in literature review, several theories and models have been discussed to study technology acceptance in healthcare

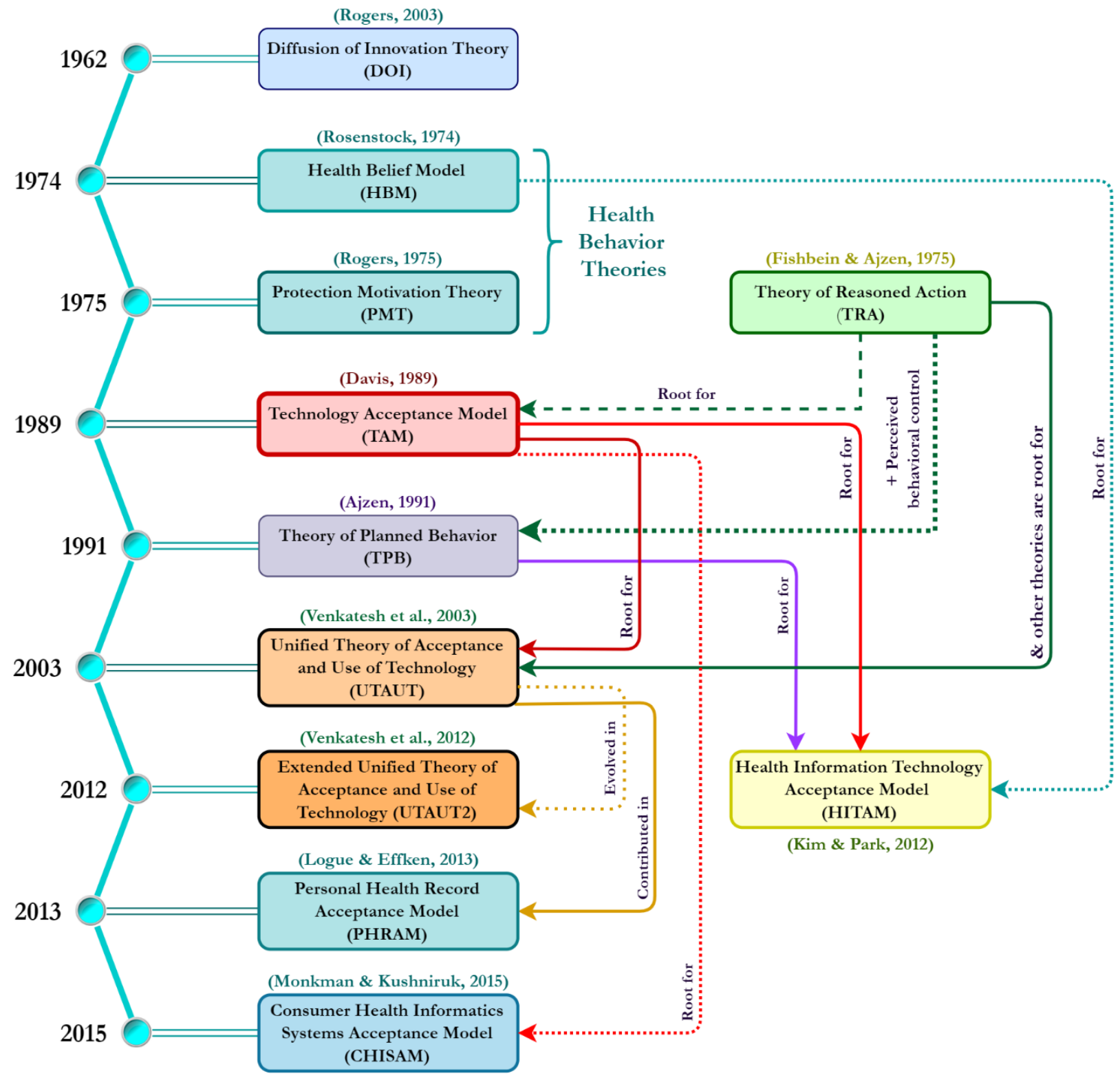

Figure 4. Theories Timeline Mapping

\section{Factors affecting adoption of ePHR}

Adoption of healthcare informatics generally and ePHR specifically from consumers perspective is a complicated process that has been identified by many factors (Najaftorkaman, 2016; Showell, 2017; Ozok et al., 2017; Abd-alrazaq et al., 2019a). In USA, a systematic review study was reviewing the factors affecting the adoption intention to use ePHR, around 59 factors related to intention to use PHR has been detected in the reviewed studies which shows how the study of this subject is very complex and affected by many variables, also the factors that affect the initial intention to use may be different from others that influence the continuity of use (Abd-alrazaq et al., 2019a).

Before mentioning these motivators and barriers in details it can be clustered and classified into higher categories, Showell defined these categories as demographic, capabilities, health related, PHR related and attitudinal factors (Showell, 2017), it has been categorized also as personal factors, human-technology interaction factors, organizational factors and social factors (Abd-alrazaq et al., 2019a). (Alzahrani \& Daim, 2019) presented a potential classification to the factors affecting adoption of tethered ePHR into seven main categories including the determinants of patients' 
intention to use ePHR for self-management in the below figure 2.20 (Alzahrani \& Daim, 2019).

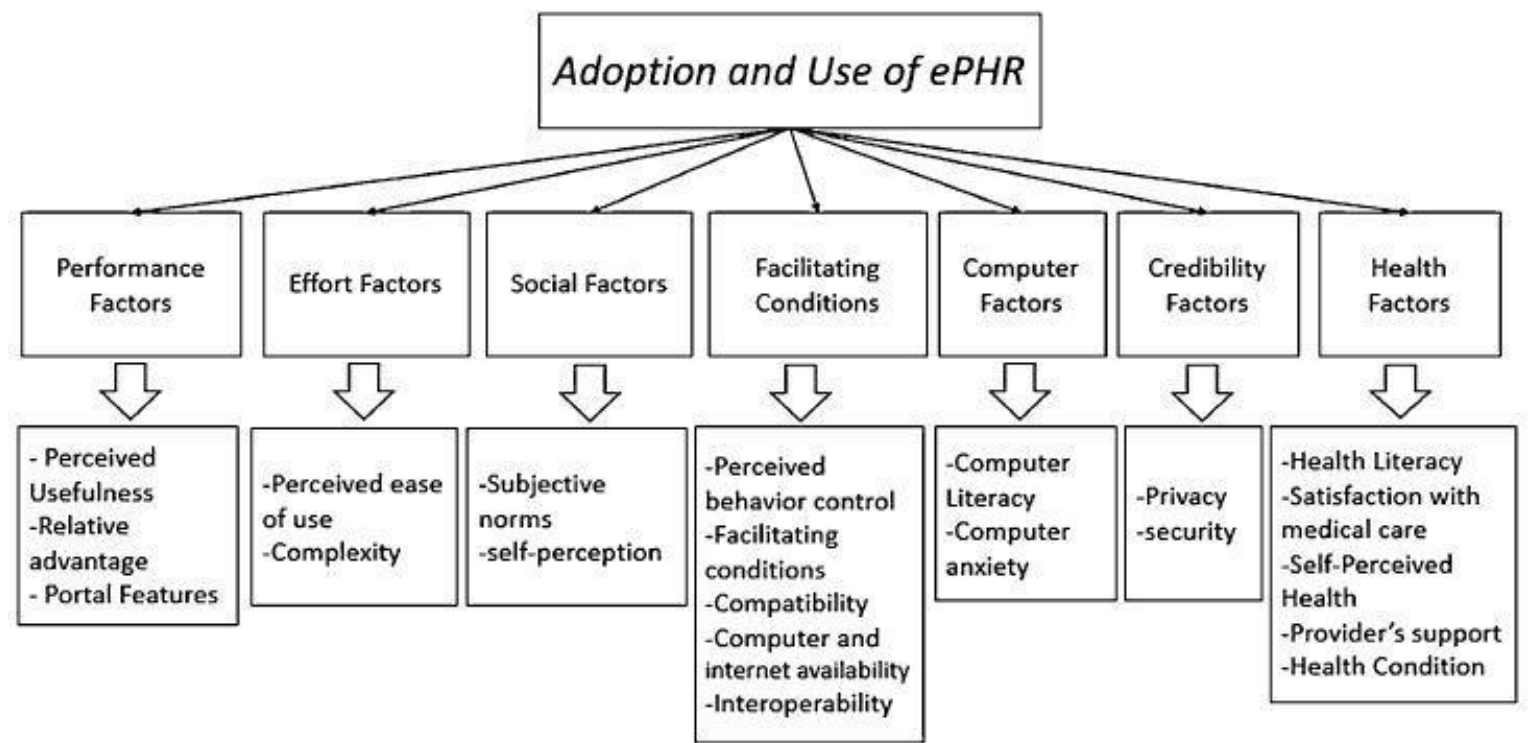

Figure 5. Taxonomy of factors related to the adoption and use of the ePHR

Source: (Alzahrani \& Daim, 2019)

Alzahrani \& Daim mentioned the most related factors to the case of tethered ePHR which might be relevant to study in the case of standalone ePHR, the following section will discuss some of the important factors that can be relevant to the current research context in Egypt. Several studies have been discussed to show the impact of each factor and the degree of significance when tested against behavioral intention.

\section{Perceived Benefits}

reviewing the literature found that several researches studied the effect of perceived benefits on the intention to use PHR as before people can use PHR they should realize its benefits and usefulness as motivator for using it. Perceived usefulness was the original factor as it was introduced firstly by (Davis, 1989) and it went through evolving of models and became performance expectancy by (Venkatesh et al., 2003).

Perceived usefulness and performance expectancy have been widely studied and proved a significance in being a predictor of intention to use new health technologies and that was also verified in the case of ePHR regardless the type of ePHR, it will be represented in the following cases with its variations and responses in different contexts.

As shown in table 1 , these studies from different contexts, countries and cultures assures that the perception of the usefulness and benefit of ePHR is a strong motivator for the intention to use by adults and needs to be studied as well in Egyptian context.

Table 1. Cases from literature handled perceived benefits of ePHR and other health applications

\begin{tabular}{|l|l|l|l|}
\hline Author/Year & Country & Variable & Significance \\
\hline (Noblin et al., 2013) & USA & Perceived Usefulness & Strongly significant \\
\hline (Cocosila \& Archer, 2014) & Canada & Perceived Usefulness & Strongly significant \\
\hline (Yuan et al., 2015) & USA & Performance Expectancy & Significant \\
\hline (Chun \& Hong, 2015) & Korea & Perceived Usefulness & Insignificant \\
\hline (Tavares \& Oliveira, 2016) & Portugal & Performance Expectancy & Significant \\
\hline (Koivumäki et al., 2017) & Finland & Performance Expectancy & Insignificant \\
\hline (Alhammad, 2017) & KSA & Perceived Usefulness & Significant \\
\hline (Hsieh et al., 2017) & Taiwan & Perceived Usefulness & Significant \\
\hline (Dutta et al., 2018) & Taiwan & Perceived Usefulness & Significant \\
\hline (Abd-Alrazaq et al., 2019b) & England & Performance Expectancy & Strongly significant \\
\hline
\end{tabular}




\section{Perceived ease of use}

usability of PHR is considered an essential determinant in the adoption process (Alzahrani \& Daim, 2019). While reviewing the literature it was found that usability of ePHR has been tested in several studies using two variables which are perceived ease of use adapted from TAM and effort expectancy adapted from UTAUT. Perceived ease of use was the original factor as it was introduced firstly by (Davis, 1989) and it went through evolving of models and became effort expectancy by (Venkatesh et al., 2003).

Perceived ease of use and effort expectancy have been tackled in several studies and proved a significance in being a predictor of intention to use new health technologies and that was also verified in the case of ePHR regardless the type of ePHR, it will be represented in the following cases with its variations and responses in different contexts.

As shown in table 2, a summary of the studies from different contexts, countries and cultures assures that perceived ease of use of ePHR is an important barrier for the intention to use and needs to be studied as well in Egyptian context.

Table 2. Cases from literature handled usability of ePHR and other health applications

\begin{tabular}{|l|l|l|l|}
\hline Author/Year & Country & Variable & Significance \\
\hline (Noblin et al., 2013) & USA & Perceived Ease Of Use & significant \\
\hline (Yuan et al., 2015) & USA & Effort Expectancy & insignificant \\
\hline (Tavares \& Oliveira, 2016) & Portugal & Effort Expectancy & Significant \\
\hline (Hsieh et al., 2017) & Taiwan & Effort Expectancy & Strongly Significant \\
\hline (Dutta et al., 2018) & Taiwan & Perceived Ease Of Use & Strongly Significant \\
\hline
\end{tabular}

\section{Privacy \& Security concerns}

One of the important concerns that has been associated with the low adoption of ePHR in several countries was the privacy and security concern, several studies reported privacy and confidentiality concerns -as people are afraid of privacy invasion of their personal health information stored in PHR, So privacy and security concerns are considered one of the factors that may hinder the adoption of PHR and affect consumer's intention to use it (Showell, 2017). Also, interoperability is considered one of the main challenges in ePHR adoption (Pagliari et al., 2007a), the required standards for building interoperable ePHRs also includes privacy and security standards (Archer et al., 2011).

As shown in table 2.5, a summary for studies from different contexts, countries and cultures discussed privacy and security concerns as barrier for adoption of ePHR, it was concluded that privacy and security might be a barrier for the intention to use and it needs to be studied as well in Egyptian context.

Table 3. Cases from literature that handled Privacy and security concerns of ePHR and other health applications

\begin{tabular}{|l|l|l|l|}
\hline Author/Year & Country & Variable & Significance \\
\hline (Pottas \& Mostert-phipps, 2013) & South Africa & Privacy \& Security Concern & Significant \\
\hline (Cocosila \& Archer, 2014) & Canada & Privacy \& Security Concern & Insignificant \\
\hline (Al-Sahan \& Saddik, 2016) & KSA & Privacy \& Security Concern & Insignificant \\
\hline (Abdekhoda et al., 2019) & Iran & Privacy \& Security Concern & Significant \\
\hline (Abd-Alrazaq et al., 2019b) & England & Privacy \& Security Concern & Significant \\
\hline
\end{tabular}

Privacy and security concern showed a significance in predicting behavioral intention in using health information technology in the consumer context although it was showing a variable effect in different contexts, but in the digital era, the extensive internet penetration and wide usage of several social media applications it might represent one of the factors that might hinder the intention to use a standalone ePHR in Egypt.

\section{eHealth Literacy}

For the adoption of ePHR by consumers, a basic level of health education is needed so consumers can have the basic knowledge about their health and they can adopt this system faster than individuals that has a little knowledge(Randeree, 2009).

The difficulty in understanding medical information and interpreting test results were significant barriers to the usage of PHR, the growing penetration of internet and the availability of health information resources encouraged the information exchange and promoted discussions about health topics. In ePHR context, eHealth literacy includes multiple aspects like normal literacy, computer literacy, health literacy and information literacy (Walsh et al., 2017). As shown in table 4, a summary of the mentioned studies that discussed eHealth literacy, The formerly discussed studies 
show the importance of eHealth literacy and its positive effect on behavioral intention. If the PHR is developed in a way that provides better understanding of medical terminologies, it may be more effective in patient engagement and better adoption rates. E-health literacy can be one of the factors that may affect the behavioral intention to use a standalone ePHR in Egypt and will be studied in this research.

Table 4. Cases from literature handled eHealth literacy in ePHR and other health applications

\begin{tabular}{|l|l|l|l|}
\hline Author/Year & Country & Variable & Significance \\
\hline (Randeree, 2009) & USA & eHealth Literacy & Significant \\
\hline (Noblin et al. 2012) & USA & eHealth Literacy & Significant \\
\hline (Otte-Trojel et al., 2016) & Systematic Review & eHealth Literacy & Significant \\
\hline (Walsh et al., 2017) & Australia & eHealth Literacy & Significant \\
\hline
\end{tabular}

This factor showed significance and a strong relationship with behavioral intention to use ePHR in the mentioned studies and might be effective in the Egyptian context.

\section{Health status}

Health status has been identified across literature as one of the ePHR adoption barriers (Showell, 2017), it is a health-related factor and it's another important factor that should be considered when it comes to the adoption of ePHR as the health status of individuals has proven to have a relationship with ePHR adoption, several studies examined the adoption of ePHR for chronically ill patients to manage their health condition and it was found that patients with chronic conditions have higher intention to use ePHR and better adoption rates than other patients with less complex conditions or healthy individuals (Alzahrani \& Daim, 2019).

As shown in table 5, several studies have discussed health status and its effect on intention to use various health information technologies, the situation is still unclear in the case of a standalone ePHR and it will be tested in the current research context to check its impact on adults' intention to use a standalone ePHR by adults in Egypt.

Table 5. Researches that handled health status

\begin{tabular}{|l|l|l|l|}
\hline Author/Year & Country & Variable & Significance \\
\hline (Britto \& Wimberg, 2009) & USA & Health Status & Significant \\
\hline (Lafky \& Horan, 2011) & USA & Health Status & Significant \\
\hline (Kim \& Park, 2012) & Korea & Health Status & Significant \\
\hline (Pottas \& Mostret-Phipps, 2013 & South Africa & Health Status & Significant \\
\hline (Al-Sahan \& Saddik, 2016) & KSA & Health Status & Insignificant \\
\hline (Tavares \& Oliveira, 2016) & Portugal & Health Status & Significant \\
\hline
\end{tabular}

Health status is one of the factors that might have a variating effect as some studies show that people with chronic diseases are more likely to use ePHR than healthy ones(Pottas \& Mostret-Phipps, 2013) while other studies showed the opposite that health status has no effect on the intention to use ePHR (Al-Sahan \& Saddik, 2016).

\section{Personalization}

Personalization is considered one of the drivers that will contribute in the sustainability of the healthcare system to provide personalized services based on the context needs, personalization is one of the key issues that help in providing better healthcare, but most of the current systems provide a personal healthcare that is designed with the approach of 'one size fits all'. It's not personalized to the context needs (Fernández-Llatas et al., 2016).

Personalization has been added as a technology related factor and adapted from several studies (Wu, 2013; Ozok et al., 2017; Tarver \& Haggstrom, 2019).

Table 6 summarizes all studies that discussed personalization, the personalization factor showed a significance in motivating people to use health information technologies including PHR, this factor might be one of the significant factors in standalone ePHR adoption in Egypt and will be considered in this research. 
Table 6. Researches that handled personalization

\begin{tabular}{|l|l|l|l|}
\hline Author/Year & Country & Variable & Significance \\
\hline (Wu, 2013) & USA & Personalization & Significant \\
\hline (Ozok, et al., 2017) & USA & Personalization & Significant \\
\hline (Tarver \& Haggstrom, 2019) & Systematic Review & Personalization & Significant \\
\hline
\end{tabular}

Personalization was identified to be one of the key issues that help providing a personalized care services according to user needs, personalizing ePHR means giving people a platform with a tailored content according to their interest and information needs, some people might need to know more information about a healthy lifestyle or a specific disease, other people living with a chronic condition might be interested in learning about their condition for a better self-management.

\section{Awareness}

Awareness in the adoption of ePHR can be divided into 2 categories, the first one is the awareness of the existence of such tool and the second one is the awareness of the benefits associated with using ePHR (Ruhi \& Majedi, 2015).

Awareness has been added as a personal factor and adapted from several studies table 7 summarizes the result of studies that discussed awareness and its effect on intention to use health information technologies.

Table 7. Cases from literature handled awareness of ePHR and other health applications

\begin{tabular}{|l|l|l|l|}
\hline Author/Year & Country & Factor & Significance \\
\hline (Wynia \& Dunn, 2010) & USA & Awareness & Significant \\
\hline (Pottas \& Mostret-Phipps, 2013) & South Africa & Awareness & Significant \\
\hline (Ruhi \& Majedi, 2015) & Canada & Awareness & Significant \\
\hline (Al-Sahan \& Saddik, 2016) & KSA & Awareness & Significant \\
\hline
\end{tabular}

As stated by other researches in Egypt that people surveyed were unaware of the existence and benefits of mobile health services and PHR as well (Amer, 2012; Mansour, 2017; Mansour, 2018)

Awareness showed a good significance in the mentioned studies to affect the behavioral intention to use eHealth services generally and ePHR specifically, the lack of awareness seems to be one of the important barriers that hinder the adoption of ePHR worldwide, it will be tested in this research context as standalone ePHR systems are a newly presented technology in Egypt.

\section{Methodology}

The paper follows a deductive approach, conducting applied research, using a quantitative research methodology to assess the variables of this model and chose a population of people who are using internet, familiar with technology and at least 18 years old. Due to time and resources constraints non-probability sampling design used through snowballing technique to collect responses of a cross sectional non-contrived online questionnaire composed of 33 questions, 6 questions for demographics and 27 questions adapted from questionnaires that have been previously tested and validated in multiple studies to test dependent variable and all independent variables.

The collected data witnessed descriptive and correlational/inferential statistical tests that identified sample characteristics, followed by inferential statistics test using SPSS software including normality test, bivariate correlation test to assess the correlations between dependent variable and all independent variables, simple linear regression to test the effect of each independent variable on the dependent variable and followed by a stepwise multiple regression test to find the most predictive variables in the model.

\section{Theoretical Framework}

The theoretical framework proposed in this research is based on an extended TAM and it was formulated after the exploration of several models that have been used in the healthcare information technology acceptance from the consumer perspective.

For this research context seven factors were proposed to affect the behavioral intention to use standalone ePHR system in Egypt shown in figure (1.1). With research proceedings it will assess the relationship these factors and behavioral intention to use standalone ePHR system in Egypt. 
Figure 3.1 shows the dependent variable in this theoretical framework which is behavioral intention and 7 independent variables that might have a direct effect on the dependent variable.

\section{Dependent Variable}

The dependent variable is Behavioral Intention (BI) which is defined as a person's "the probability a person consciously makes future arrangements to do (or not to do) a specific behavior" (Warshaw \& Davis, 1985).

\section{Independent variables}

Perceived Usefulness (PU)

Perceived usefulness (PU) can be defined as "the degree to which a person believes that using a particular system would enhance his or her job performance" (Davis, 1989).

\section{Perceived Ease Of Use (PEOU)}

Perceived ease of use (PEOU) can be defined as "the degree to which a person believes that using a particular system would be free of effort" (Davis, 1989).

\section{Privacy \& Security (PS)}

This construct can be defined in the scope of perceived data privacy concerns and perceived security concerns.

In this context, privacy can be defined as the degree to which individuals believe that ePHR should protect their identifiable health information and regulate the health information exchange among persons and entities, While perceived security can be defined as the degree to which individuals belief that ePHR should have the physical, technological and security tools to protect health information from unauthorized access (U.S department of health and human services, 2008).

\section{eHealth Literacy (eHL)}

Health literacy in general refers to "the degree to which individuals have the capacity to obtain, process, and understand basic health information and services needed to make appropriate health decisions." (Ratzan et al., 2000).

In a health information technology context eHealth literacy refers to "the ability to seek, find, understand and appraise health information from electronic sources and apply the knowledge gained to addressing or solving health problems" (Norman \& Skinner, 2006).

\section{Health Status (HS)}

Health status can be defined as "a measure of how individuals perceive their own health through personal observation by rating it as excellent, very good, good, fair, or poor" (Akubuiro, 2018).

\section{Personalization (PN)}

Personalization can be defined as "the practice of dynamically altering content according to the profile, preferences, and usage patterns of an individual user" (Eng, 2001).

\section{Awareness (AW):}

Awareness can be defined as all knowledge that is accessible and can be integrated into a coherent picture, when required, to assess and cope with a situation (Sarter \& Woods, 1991). 


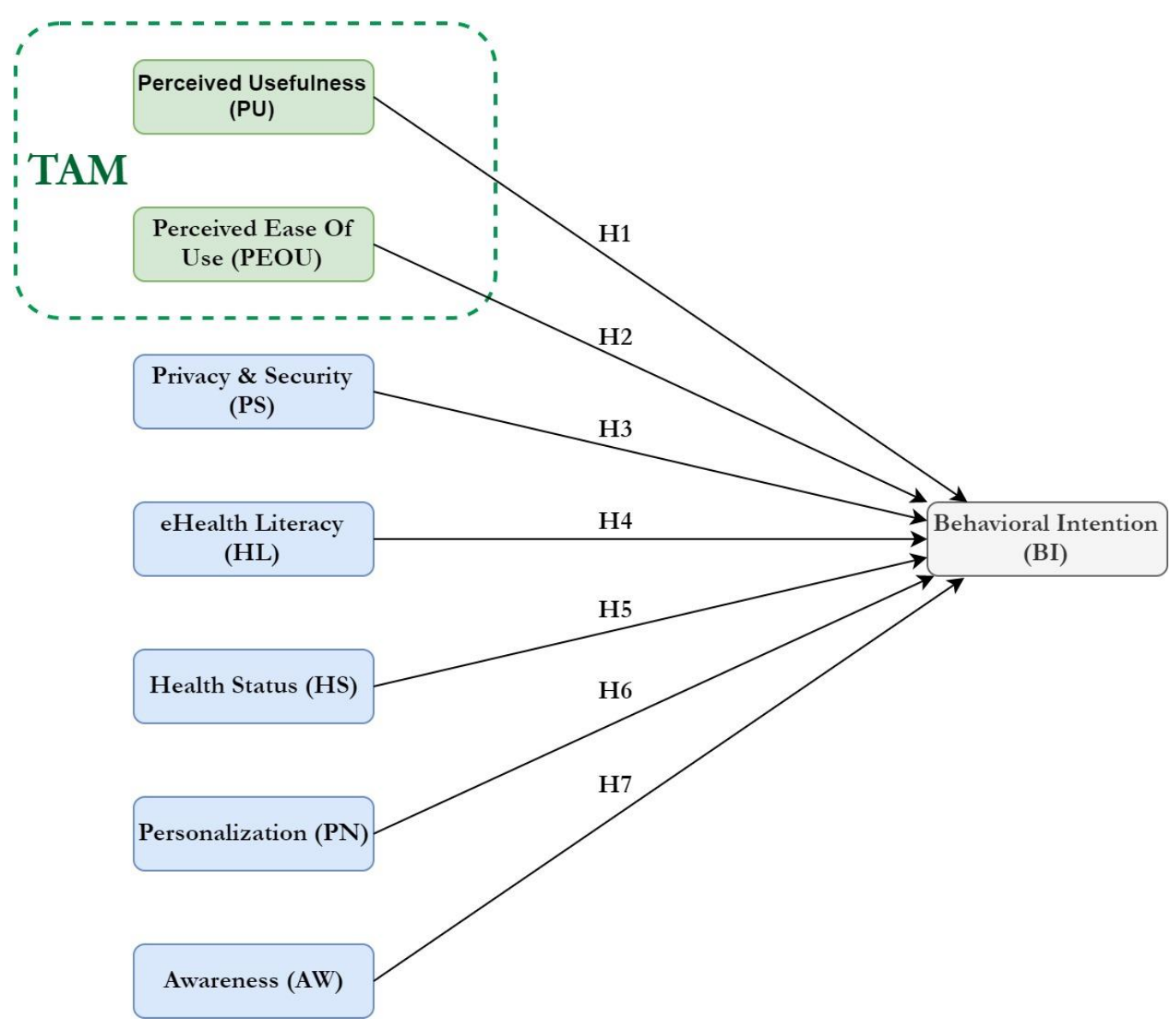

Figure 6. Proposed Research Model

\section{Hypothesis}

H10: There is no effect of perceived usefulness on behavioral intention to use a standalone ePHR system by adults in Egypt.

H1a: There is an effect of perceived usefulness on behavioral intention to use a standalone ePHR system by adults in Egypt.

H20: There is no effect of perceived ease of use on behavioral intention to use a standalone ePHR systems by adults in Egypt.

H2a: There is an effect of perceived ease of use on behavioral intention to use a standalone ePHR system by adults in Egypt.

H30: There is no effect of (Privacy \& security) concerns on behavioral intention to use a standalone ePHR system by adults in Egypt.

H3a: There is an effect of privacy and security on behavioral intention to use a standalone ePHR system in Egypt.

H40: There is no effect of eHealth literacy on behavioral intention to use a standalone ePHR system by adults in Egypt.

H4a: There is an effect of eHealth literacy on behavioral intention to use a standalone ePHR system by adults in Egypt.

H50: There is no effect of health status on behavioral intention to use a standalone ePHR system by adults in Egypt.

H5a: There is an effect of health status on behavioral intention to use a standalone ePHR system by adults in Egypt.

H60: There is no effect of personalization on behavioral intention to use a standalone ePHR system by adults in Egypt.

H6a: There is an effect of personalization on behavioral intention to use a standalone ePHR system by adults in Egypt.

H70: There is no effect of awareness on behavioral intention to use a standalone ePHR system by adults in Egypt.

H7a: There is an effect of awareness on behavioral intention to use a standalone ePHR system by adults in Egypt. 


\section{Discussion and Findings}

\section{Descriptive Statistics}

In this research, the researcher was able to collect 254 valid responses only without any missing values to test their perceptions regarding the usage of ePHR from several dimensions. The main objective of this study was to determine the factors that influence the behavioral intention of adults in Egypt to use a standalone ePHR systems and applications.

The survey items included questions that collect demographics of participants data and other items that tested 7 independent variables and 1 dependent variable.

The gender distribution in the collected data was near where $56 \%$ was male and $46 \%$ female, also the sample age distribution was $76 \%$ of the sample ranging from 18 to 40 years old. Around $71 \%$ of the collected data were located in the biggest 3 cities Cairo, Giza and Alexandria. Around $85 \%$ of the sample are highly educated with at least university degree and $15 \%$ with a high school or equivalent degree. From the collected data $84 \%$ stated that they don't suffer from any chronic condition and only $16 \%$ suffer from chronic condition, also the researcher found that the usage of ePHR systems was very low since $11 \%$ of the sample only stated that they are using ePHR systems and $89 \%$ are non-users.

From the demographics analysis the researcher concluded that this sample is more representing for young adults who are ranging from 18 to 40 years old while the elder adults were a minority in this sample. Also, majority of the participants were highly educated with at least university degree.

Most of the survey respondents are not using ePHR systems which reflect a very low adoption rate of such systems and this validates the significance of this research, this result came in consistency with (Mansour, 2018) since only $40 \%$ only of his sample were using tethered and almost none of them is using standalone ePHR applications

From the dependent variable analysis, the researcher found that the mean of behavioral intention was 3.23 which indicates that most of the survey respondents are tending to agree to use standalone ePHR applications which reflects a true demand of ePHR applications if it's available for them, this result came in consistency with Badran since she found 80\% of her sample are willing to use EHR services if introduced in the Egyptian market (Badran, 2019), this result also reflects another dimension of the importance of this research to find out the gap between the high demand and low adoption of this service in Egypt and what are the factors that can motivate or hinder the adoption intention of adults in Egypt.

From the analysis of independent variables, the researcher found that respondents of the survey were tending to agree that using standalone ePHR systems would be useful to manage their health information and would increase their efficiency since the mean of perceived usefulness variable was 3.33.

Respondents of the survey were tending to agree that standalone ePHR systems would be easy to use and learn, also they expect that these systems would not be difficult to use since the mean of perceived ease of use variable was 3.27.

Respondents of the survey were tending to slightly agree that using standalone ePHR systems might cause loss of their privacy and their health data might be vulnerable to unauthorized access or stolen by internet hackers since the mean of privacy and security variable was 2.57

Respondents of the survey were tending to slightly agree that they can use the internet in finding helpful information regarding their health and how to use such information after the evaluation of information source whether it's credible or not, the mean of eHealth literacy variable was 2.66 .

$87 \%$ of the survey respondents rated their health status at least good and the mean of health status variable was 1.95.

Since the mean of personalization variable 3.17, respondents of the survey were tending to agree that personalized standalone ePHR systems could achieve a better fit for their needs and increase their efficiency and spending less time in managing their health information data.

Respondents of this survey were tending to disagree on being aware enough about the existence of standalone ePHR applications and they know little information about its benefits which made them unable to decide whether to use it or not, the mean of awareness variable was 2.25 .

\section{Hypotheses Testing}

In this research, seven independent variables effect have been tested on the behavioral intention to use standalone ePHR systems by adults in Egypt. The researcher used Pearson correlation test to initially discover the existing relationships and the degree of association between dependent variable and independent variables, then a simple linear regression was carried to measure the effect of each independent variable on the dependent variable and answer the research hypotheses.

Additional stepwise multiple regression test was carried out to check the model fit and identify the most powerful 
predictors in the model in presence of all variables together.

The results shown in table 8 summarize the answers to all hypotheses that were proposed by the researcher and can be outlined as following:

Table 8. Summary of hypothesis testing

\begin{tabular}{|l|l|l|l|}
\hline Alternative Hypothesis & Test Name & $\begin{array}{l}\text { Test Result On The Null } \\
\text { Hypothesis }\end{array}$ & P-value \\
\hline H1a & Simple linear regression & Rejected & $<0.001$ \\
\hline H2a & Simple linear regression & Rejected & $<0.001$ \\
\hline H3a & Simple linear regression & Rejected & 0.001 \\
\hline H4a & Simple linear regression & Rejected & 0.003 \\
\hline H5a & Simple linear regression & Failed to reject & 0.833 \\
\hline H6a & Simple linear regression & Rejected & $<0.001$ \\
\hline H7a & Simple linear regression & Rejected & 0.009 \\
\hline
\end{tabular}

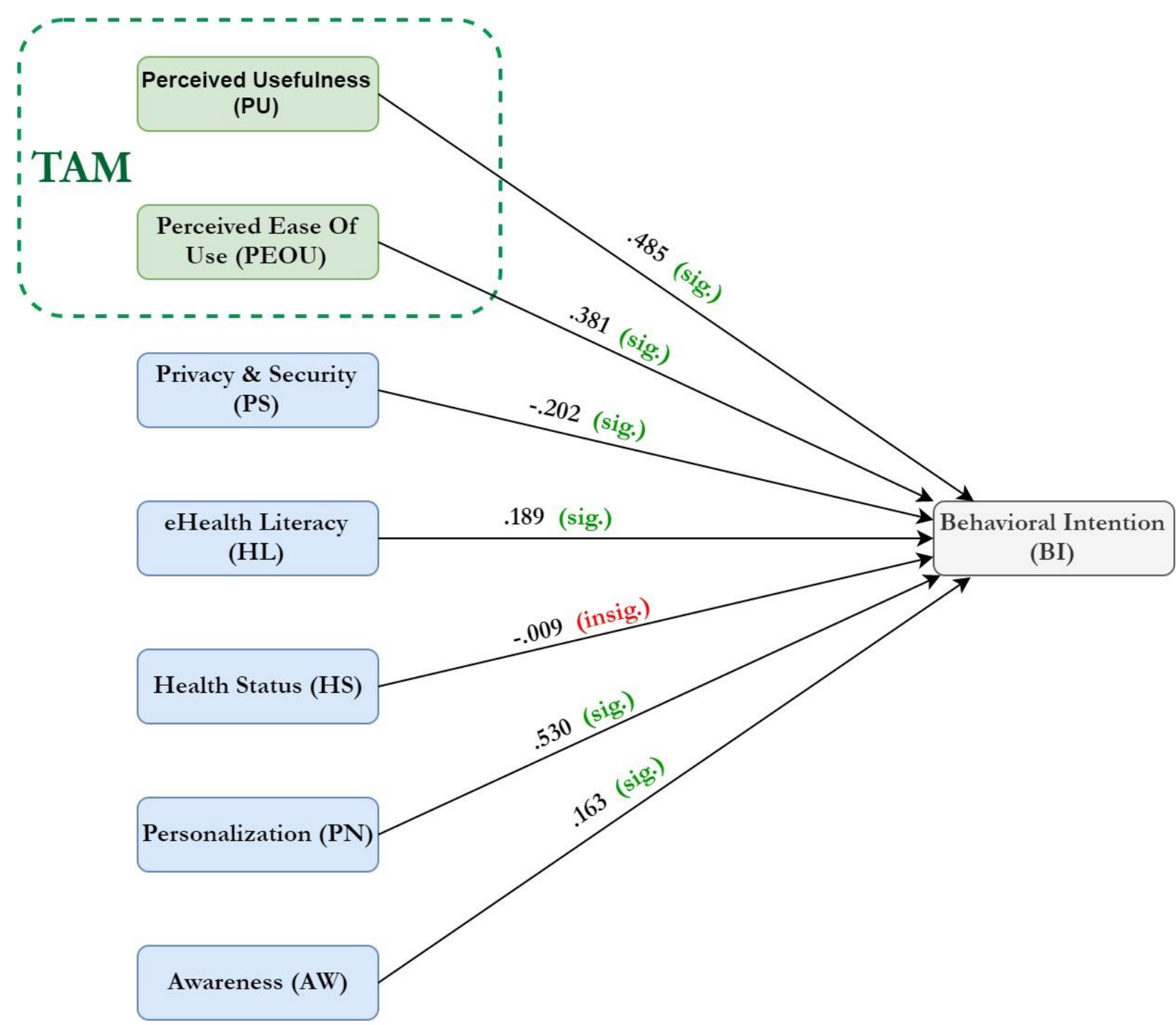

Figure 7. Results of Simple Linear Regression Analysis 
In figure 7, all results from simple linear regression test are shown and the researcher has found the following:

Perceived usefulness was found to have a significant positive effect on behavioral intention to use standalone ePHR systems by adults in Egypt and it was one of the strongest predictors in the model, this result came in consistency with other researchers from different contexts worldwide (Noblin et al., 2013; Cocosila \& Archer, 2014; Yuan et al., 2015; Tavares and Oliveira, 2016; Alhammad, 2017; Hsieh et al., 2017; Dutta et al., 2018; Abd-Alrazaq et al., 2019b), this result assures the importance of perceived usefulness as a predictor of behavioral intention in the consumer health informatics context. The result also came contradicting with other studies (Chun \& Hong, 2015; Koivumäki et al., 2017), they found perceived usefulness has insignificant effect on behavioral intention to adopt ePHR systems by younger adults but the situation in Egypt was different since the sample in this research had more than $75 \%$ of respondents ranging from 18 to 40 years old. The result is consistent with the result from KSA that respondents have shown good interest in ePHR systems reflects the similarity of context as Egypt and KSA are 2 Arabian countries from the middle east.

Perceived ease of use was found to have a significant positive effect on behavioral intention to use standalone ePHR systems by adults in Egypt, despite its moderate effect on behavioral intention it was not included as one of the strong predictors in the stepwise multiple regression test, this result might be due to that majority of the survey respondents were from younger age that ranges from 18 to 40 years old, mostly this age is familiar with using technology and new applications so they might not find a big problem in using standalone ePHR systems from the ease of use perspective but it still has a significant effect on behavioral intention. This result came in consistency with several studies (Noblin et al., 2013; Tavares and Oliveira, 2016; Hsieh et al., 2017), the result was contradicting with other study (Yuan et al., 2015) where effort expectancy had insignificant effect on behavioral intention of continued usage of health and fitness apps.

Privacy and security concerns were found to have a significant negative effect on behavioral intention to use standalone ePHR systems by adults in Egypt, this result came in consistency with several studies in literature (Pottas \& Mostert-phipps, 2013; Abdekhoda et al., 2019; Abd-Alrazaq et al., 2019b ), the result in this research was contradicting with other studies from literature (Cocosila \& Archer, 2014; Al-Sahan \& Saddik, 2016) which found insignificant effect of privacy and security concerns on behavioral intention, the result indicated a small direct effect of privacy and security concerns on behavioral intention which means that privacy and security concerns are representing a barrier for standalone ePHR adoption but without a major impact, however it should be handled with care to overcome its negative effect on behavioral intention.

eHealth literacy was found to have a significant positive effect on behavioral intention to use standalone ePHR systems by adults in Egypt, this result came in consistency with other studies from literature (Randeree, 2009; Noblin et al. 2012; Otte-Trojel et al., 2016; Walsh et al., 2017), the result showed a small direct effect of eHealth literacy on behavioral intention which means that people with higher eHealth literacy have a slightly higher intention to use ePHR applications, eHealth literacy is still considered a motivator for standalone ePHR system adoption.

Health status was found to have insignificant effect on behavioral intention to use standalone ePHR systems by adults in Egypt, this result came in consistency with a study from KSA (Al-Sahan \& Saddik, 2016) where the researchers found most of survey participants are interested in using ePHR regardless of their health status and this might be due to culture similarities in both contexts, the result is contradicting with other studies from literature (Britto \& Wimberg, 2009; Lafky \& Horan, 2011; Pottas \& Mostret-Phipps, 2013; Tavares \& Oliveira, 2016), from the discussed result the researcher found that health status is not a barrier for standalone ePHR in Egypt since it doesn't have any effect on behavioral intention.

Personalization was found to have a strong significant positive effect on behavioral intention to use standalone ePHR systems by adults in Egypt and it was the strongest predictor of behavioral intention in comparison with all other independent variables in this research, this result came in consistency with several studies worldwide (Wu, 2013; Ozok, et al., 2017), this finding indicates that personalization is one of the valuable predictors that has a strong effect on behavioral intention to use standalone ePHR systems by adults in Egypt, providing a personalized standalone ePHR system that fit user's specific needs in self-management might achieve a better adoption and leverage the utilization of these applications towards a meaningful use.

Awareness was found to have a significant positive effect on behavioral intention to use standalone ePHR systems by adults in Egypt, this result came in consistency with several studies from literature (Wynia \& Dunn, 2010; Pottas \& Mostret-Phipps, 2013; Al-Sahan \& Saddik, 2016), the lack of awareness might interfere the decision making about using standalone ePHR and better awareness of these systems and its benefits to enough extent might motivate people to use these applications, despite the small effect of awareness on behavioral intention but it might reflect a logical fact of the gap between the high demand and low adoption idea, although some people were aware about the existence of 
these systems but they don't use it, but awareness still have a significant positive effect that reflects a higher intention to use with better awareness.

Finally, a preliminary impression has been acquired about the current situation of standalone ePHR adoption in Egypt, this research tested 7 independent variables of importance to check their effect on behavioral intention and 6 out of 7 was found to have a significant effect on behavioral intention, while only health status didn't have a significant effect on behavioral intention which is also good outcome as it revealed the good demand of ePHR applications by adults regardless of their health status. Perceived usefulness and personalization were the strongest predictors among all variables and represent a strong motivator for the adoption process.

\section{Extended Analysis}

The results of simple linear regression showed that all variables have a direct significant effect on behavioral intention except health status variable which was an insignificant predictor of behavioral intention.

The researcher carried out a stepwise multiple regression analysis to detect the most effective variables and test all independent variables together in the research model and it was found that only perceived usefulness and personalization have a significant direct effect on behavioral intention while PEOU, PS, eHL and AW don't have a significant direct effect on behavioral intention when this model was tested altogether.

The researcher performed a mediation analysis to reveal the reason behind losing the direct significant effect of PEOU, PS, eHL and AW since these variables might have an indirect effect mediated with PN or PU or both variables.

It was found that Perceived Ease Of Use (PEOU) is a direct significant positive predictor of PU and PN, PEOU has an insignificant direct effect on $\mathrm{BI}$ in presence of $\mathrm{PU}$ and $\mathrm{PN}$ and it has indirect significant effect on behavioral intention mediated by PU and PN, this result is consistent with the result from stepwise multiple regression that PU and PN are the direct predictors of $\mathrm{BI}$ in this model and PEOU has insignificant direct effect on $\mathrm{BI}$, this result indicates that standalone ePHR systems with better ease of use will enhance the perceived usefulness of these systems and makes people with a higher demand for more personalized systems, and consequently will lead to a higher behavioral intention to use these systems.

The results showed that Privacy and Security (PS)variable has a direct significant negative effect on PU and PN, PS has insignificant direct effect on $\mathrm{BI}$ in presence of $\mathrm{PU}$ and $\mathrm{PN}$ and it has indirect significant negative effect on behavioral intention mediated by PU and PN, this result is consistent with the result from stepwise multiple regression that PU and PN are the direct predictors of BI in this model and PS has insignificant direct negative effect on BI, this result indicates that people who have higher privacy and security concerns will negatively affect perceived usefulness of standalone ePHR systems and makes people less interested in personalized systems, and consequently will lead to lower behavioral intention to use these systems.

It was found that eHealth Literacy (eHL) is a direct significant positive predictor of PU and PN, eHL has an insignificant direct effect on $\mathrm{BI}$ in presence of $\mathrm{PU}$ and $\mathrm{PN}$ and it has an indirect significant positive effect on behavioral intention mediated by $\mathrm{PU}$ and $\mathrm{PN}$, this result is consistent with the result from stepwise multiple regression that PU and $\mathrm{PN}$ are the direct predictors of $\mathrm{BI}$ in this model and eHL has an insignificant direct effect on $\mathrm{BI}$, this result indicates that people with higher health literacy will perceive standalone ePHR systems more useful to them and makes people more interested in personalized systems, and consequently will lead to a higher behavioral intention to use these systems.

The results showed that Awareness (AW) is a direct significant positive predictor of $\mathrm{PU}$ and $\mathrm{PN}$, AW has an insignificant direct effect on $\mathrm{BI}$ in presence of PU and PN and it has indirect significant effect on behavioral intention mediated by PU and PN, this result is consistent with the result from stepwise multiple regression that PU and PN are the direct predictors of $\mathrm{BI}$ in this model and $\mathrm{AW}$ has an insignificant direct effect on $\mathrm{BI}$, this result indicates that better awareness about standalone ePHR systems will enhance the perceived usefulness of these systems and makes people more interested in using personalized standalone ePHR systems, and consequently will lead to a higher behavioral intention to use these systems.

It was found that Health Status (HS) is an insignificant predictor of PU but it has a direct significant positive effect on $\mathrm{PN}$, HS has an insignificant direct effect on BI from the simple linear regression analysis and in presence of PN and it has an indirect insignificant effect on behavioral intention, this result assures that there is no direct or indirect effect of health status on behavioral intention but indicates that people with a poorer perceived health status will be more interested in personalized standalone ePHR systems than other people with better perceived health status and consequently will lead to a higher behavioral intention to use these systems.

After testing the mediation effect of perceived usefulness and personalization on all other independent variables, figure 8 shows the suggested model based on the results from the mediation analysis. 
Extended analysis results revealed that relationships are more complex and need a comprehensive investigation to discover relationships among all independent variables.

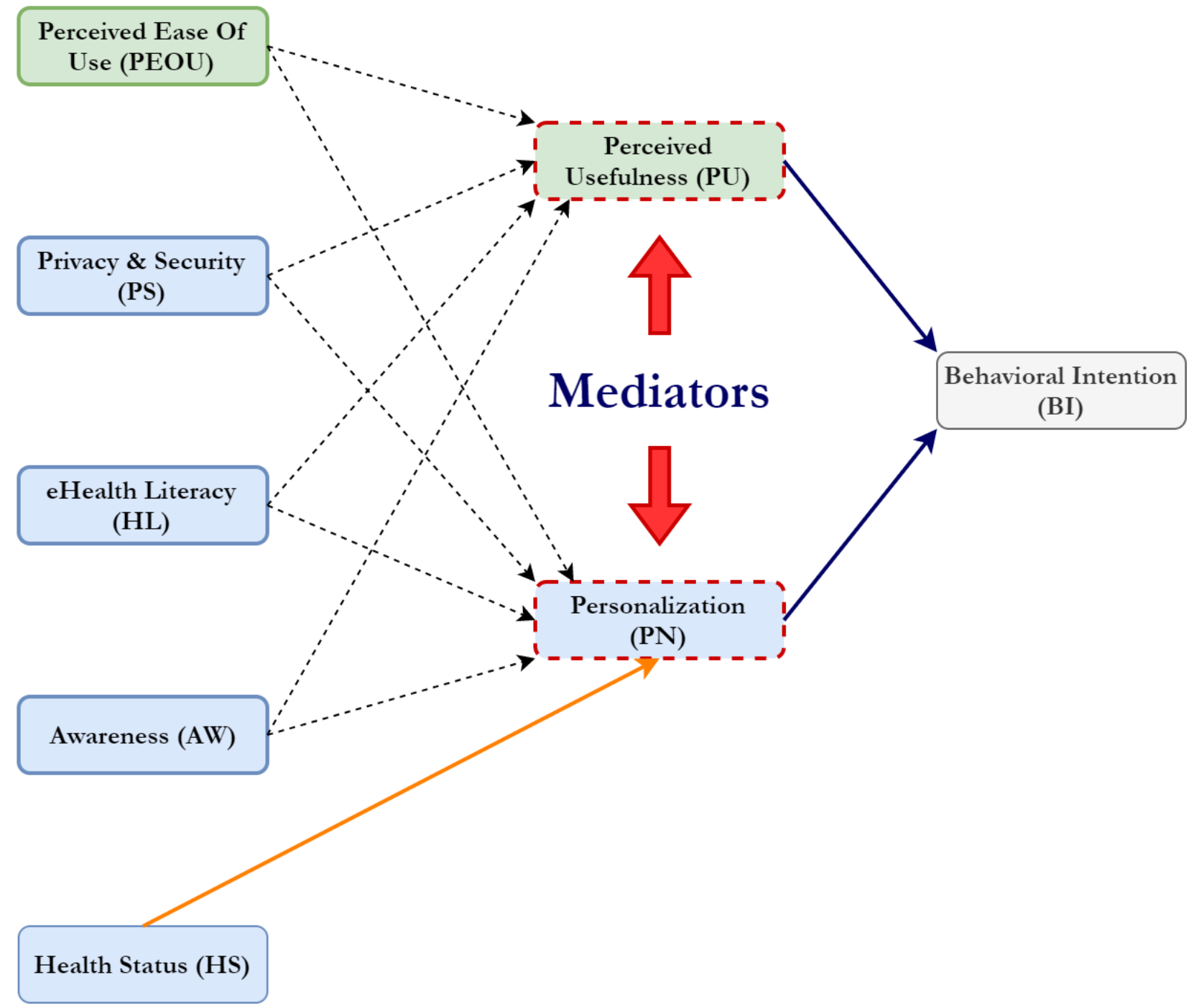

\section{Conclusion}

Figure 8. Suggested Model After Extended Analysis

the Egyptian future of health is going towards the digital transformation in all sectors including patient engagement and health information exchange, all that was found pointed to the importance of studying this topic due to its importance on several levels, one of the clues was that standalone ePHR applications are already available for use in the market with a very low adoption rate although there is a demand detected in the Egyptian market found by previous researchers, the responsiveness of healthcare consumers is still slower than expected, this research outlines some of the factors that created this gap between demand and usage.

Findings in this research revealed that adoption rate in Egypt is still very low and high demand for this service which makes this research is significant as it's trying to find out the reasons behind this gap, perceived usefulness, perceived ease of use, (privacy and security), eHealth literacy, personalization and awareness had a significant impact on behavioral intention to use standalone ePHR applications. Personalization was found to have the strongest effect on behavioral intention followed by perceived usefulness. Health status was found to have an insignificant effect on behavioral intention which indicates the interest of people with different health statuses in standalone ePHR.

In an additional analysis, it was found that personalization and perceived usefulness mediated the effect of perceived ease of use, (privacy and security), eHealth literacy and awareness on behavioral intention which resulted in a recommended model from a scientific point of view that needs to be investigated through a comprehensive study to discover more information about relationships among independent variables. 


\section{Recommendations}

\section{Implications and recommendations for science}

This research provides a test for extended technology acceptance model and assures the validity of extending TAM and its ability on adding further dimensions that influence behavioral intention in consumer health informatics including health-related variables, personal related variables and technology-related variables.

\section{Implementation recommendations for industry business professionals}

it's recommended to make sure that marketing campaigns focus on the usefulness and how people can benefit from using it as it can bring a better health outcome. Patient education about the value of using ePHR is also important and delivering personalized messages to each segment that can fit their own needs.

it's recommended that technology providers present a user-friendly interface that would be easy to use and learn, this will encourage users for using this application especially that the health context might be complicated somehow.

it's recommended to put a clear privacy policy in applications or websites that provide ePHR services that guarantee the privacy and confidentiality of consumer's health information, giving a part of the focus in delivering marketing messages that make people feel safe about putting their health information in standalone ePHR.

the design of understandable information inside ePHR by providing user guides about the existing medical information that might facilitate the understandability of health information.

Providing applications that can be personalized according to user's needs, giving users the option to store the data by multiple means like manual entry, uploading electronic documents and capturing images of health and medical documents for easier storage, also providing a personalized source of information inside standalone ePHR application is very beneficial so people with different interests in health can find relevant information regarding their health, the ability to create communities who share the same interest in the application so they can communicate and share their experience.

marketing campaigns to focus on giving better awareness about what features and benefits this application will provide during its usage, providing information about how the application can fit user's needs by the ability to be personalized according to the interest of the user.

\section{Future Work}

The lack of studies tackling this topic in Egyptian context requires more extended research by using larger sample size or handling different aspects of using ePHR systems, Since this study is just focusing on adoption of standalone ePHR applications, further researches are needed to study other types of ePHR systems like tethered ePHR systems. the complexity of this research topic requires more factors to be explored and tested to uncover the unexplained variance in behavioral intention, more researches are needed to be conducted on people suffering from chronic diseases, new researches are required to study the behavioral intention to use ePHR systems by healthcare professionals either for self-management or for professional purposes, comparative studies are needed to compare users and non-users of standalone ePHR applications to reveal any differences in the factors that affect their intention to use this service. New studies should focus on elderly people since they were the least percentage of participants in this research.

\section{References}

Abd-alrazaq, A. A., Bewick, B. M., Farragher, T., \& Gardner, P. (2019a). Factors that affect the use of electronic personal health records among patients: A systematic review. International journal of medical informatics. https://doi.org/10.1016/j.ijmedinf.2019.03.014

Abd-Alrazaq, A., Bewick, B. M., Farragher, T., \& Gardner, P. (2019b). Factors Affecting Patients' Use of Electronic Personal Health Records in England: Cross-Sectional Study. Journal of medical Internet research, $21(7)$, e12373. https://doi.org/10.2196/12373

Abdekhoda, M., Dehnad, A., \& Khezri, H. (2019). The effect of confidentiality and privacy concerns on adoption of personal health record from patient's perspective. Health and Technology, 1-7. https://doi.org/10.1007/s12553-018-00287-z

AHIMA e-HIM Personal Health Record Work Group. (2005). Defining the Personal Health Record. Journal of AHIMA 76, no.6, 24-25. Available at: https://library.ahima.org/doc?oid=59377\#.XQgLAIgzZPY

Akubuiro, J. O. (2018). A Quantitative Study of the Factors Affecting Health Care Technology Use in the Millennial Generation (Doctoral dissertation). Northcentral University, San Diego, California, USA.

Alhammad, O. S. (2017). ASSESSING OUTPATIENTS'ATTITUDES AND EXPECTATIONS TOWARDS ELECTRONIC 
PERSONAL HEALTH RECORDS (ePHR) SYSTEMS IN SECONDARY AND TERTIARY HOSPITALS IN RIYADH, SAUDI ARABIA (Doctoral dissertation).

Al-Sahan A MSc (HI), \& Saddik B PhD, MPH. (2016). Perceived challenges for adopting the Personal Health Record (PHR) at Ministry of National Guard Health Affairs (MNGHA)- Riyadh. Online journal of public health informatics, 8(3), e205. https://doi.org/10.5210/ojphi.v8i3.6845

Alyami, M. A. \& Song, Y. T. (2016). Removing barriers in using personal health record systems. In 2016 IEEE/ACIS 15th International Conference on Computer and Information Science (ICIS) (pp. 1-8). IEEE. https://doi.org/10.1109/ICIS.2016.7550810

Alzahrani, S., \& Daim, T. (2019). Assessing the Key Factors Impacting the Adoption and Use of Tethered Electronic Personal Health Records for Health Management. In $R \& D$ Management in the Knowledge Era, pp. 373-396. Springer, Cham. https://doi.org/10.1007/978-3-030-15409-7_15

Amer, M. (2012). Determinants of Users Adoption of Mobile Healthcare Services in Egypt. (Unpublished Master's thesis). Maastricht School of Management, Netherlands.

Andrikopoulou, E., Scott, P. J., \& Herrera, H. (2018). Important design features of personal health records to improve medication adherence for patients with long-term conditions: protocol for a systematic literature review. JMIR research protocols, 7(6), p.e159. https://doi.org/10.2196/resprot.9778

Archer, N., Fevrier-Thomas, U., Lokker, C., McKibbon, K. A., \& Straus, S. E. (2011). Personal health records: a scoping review. Journal of the American Medical Informatics Association, 18(4), 515-522. https://doi.org/10.1136/amiajnl-2011-000105

Badran, M. F. (2019). eHealth in Egypt: The demand-side perspective of implementing electronic health records. Telecommunications Policy, 43(6), 576-594. https://doi.org/10.1016/j.telpol.2019.01.003

Britto, M. T., \& Wimberg, J. (2009). Pediatric personal health records: current trends and key challenges. Pediatrics, 123(Supplement 2), S97-S99. https://doi.org/10.1542/peds.2008-1755I

Chun, J. R. (2015). Hong aHG. Factors affecting on personal health record. Indian Journal of Science and Technology, 8(S8), 173-9. https://doi.org/10.17485/ijst/2015/v8iS8/70534

Cocosila, M., \& Archer, N. (2014). Perceptions of chronically ill and healthy consumers about electronic personal health records: a comparative empirical investigation. BMJ open, 4(7), e005304. https://doi.org/10.1136/bmjopen-2014-005304

Davis, F. (1989). Perceived Usefulness, Perceived Ease of Use, and User Acceptance of Information Technology. MIS Quarterly, 13(3), 319-340. https://doi.org/10.2307/249008

Demiris, G. (2016). Consumer Health Informatics: Past, Present, and Future of a Rapidly Evolving Domain. Yearbook of medical informatics, Suppl 1(Suppl 1), S42-S47. https://doi.org/10.15265/IYS-2016-s005

Dutta, B., Peng, M. H., \& Sun, S. L. (2018). Modeling the adoption of personal health record (PHR) among individual: the effect of health-care technology self-efficacy and gender concern. Libyan Journal of Medicine, 13(1). https://doi.org/10.1080/19932820.2018.1500349

Elsafty, A. (2018). Lecture 2: Scientific Business Research Problem Definition [PowerPoint slides]. Retrieved from Maastricht School of Management, MBA Degree.

Elsafty, A. (2018). Lecture 2: Scientific Business Research Problem Definition [Lecture]. Retrieved from Maastricht School of Management, MBA Degree.

Elsafty, A. (2020). DrAshrafElsafty Channel. Retrieved from Youtube https://www.youtube.com/watch?v=y-jDT2iOOhU\&list=PLKSWZdnzp8p3uFLLh2N8_d0W7ZmJDLMjW\&index $=42 \& \mathrm{t}=628 \mathrm{~s}$

Elsafty, A., \& AlNawaly, A. (2020). Role of Co-Working Spaces' Services in Entrepreneurs Growth in Upper Egypt, The Case of Step Co-Working Space. Business and Management Studies, 6(2), June 2020. ISSN: 2374-5916 E-ISSN: 2374-5924. https://doi.org/10.11114/bms.v6i2.4898

Elsafty, A., Abadir, D., \& Shaarawy, A. (2020). How Does the Entrepreneurs' Financial, Human, Social and Psychological Capitals Impact Entrepreneur'S Success?. Business and Management Studies, 6(3), 55-71. https://doi.org/10.11114/bms.v6i3.4980

Elsafty, A., Elsayed, H., \& Shaaban, I. (2020), A Business Analysis Perspective for Engineering Education in Egypt. Journal of Education and Training Studies, 8(5), May 2020. ISSN 2324-805X E-ISSN 2324-8068. 
https://doi.org/10.11114/jets.v8i5.4721

Elsafty, A., Elsayed, H., \& Shaaban, I. (2020). Educating Engineering Students in Egypt: Recommendations for Improvement. International Journal of Higher Education. https://doi.org/10.5430/ijhe.v9n3p1

Elsafty, A., Elsayed, H., \& Shaaban, I. (2020). Journal of Education and Training Studies, 8(8), August 2020. ISSN 2324-805X E-ISSN 2324-8068. https://doi.org/10.11114/jets.v8i8.4901

Elsafty, A., Ragheb, M. (2020). Role of Human Resource Management towards Employees Retention during Covid-19 Pandemic. Business and Management Studies, 6(2), June 2020. ISSN: 2374-5916 E-ISSN: 2374-5924. https://doi.org/10.11114/bms.v6i2.4899

Eng, T. R. (2001). The eHealth Landscape: A Terrain Map of Emerging Information and Communication Technologies in Health and Health Care. Princeton, NJ: Robert Wood Johnson Foundation.

Fernández-Llatas, C., Martinez-Romero, A., Bianchi, A. M., Henriques, J., Carvalho, P., \& Traver, V. (2016, February). Challenges in personalized systems for Personal Health Care. In 2016 IEEE-EMBS International Conference on Biomedical and Health Informatics (BHI) (pp. 356-359). IEEE. https://doi.org/10.1109/BHI.2016.7455908

Ford, E. W., Hesse, B. W., \& Huerta, T. R. (2016). Personal health record use in the United States: forecasting future adoption levels. Journal of medical Internet research, 18(3), e73. https://doi.org/10.2196/jmir.4973

Fuji, K. T., Abbott, A. A., Galt, K. A., Drincic, A., Kraft, M., \& Kasha, T. (2012). Standalone personal health records in the United States: meeting patient desires. Health and technology, 2(3), 197-205. https://doi.org/10.1007/s12553-012-0028-1

Hsieh, H. L., Kuo, Y. M., Wang, S. R., Chuang, B. K., \& Tsai, C. H. (2017). A study of personal health record user's behavioral model based on the PMT and UTAUT integrative perspective. International journal of environmental research and public health, 14(1), 8. https://doi.org/10.3390/ijerph14010008

Kaelber, D., \& Pan, E. C. (2008). The value of personal health record (PHR) systems. In AMIA Annual Symposium Proceedings (Vol. 2008, p. 343). American Medical Informatics Association.

Katehakis, D., \& Kouroubali, A., \& Karatzanis, I., \& Manousos, D., \& Kondylakis, H., \& Kavlentakis, G., ... Marias, K. (2018). Personal Health ICT Systems to Support Integrated Care Solutions.

Kim, J., \& Park, H. A. (2012). Development of a health information technology acceptance model using consumers' health behavior intention. Journal of medical Internet research, 14(5), e133. https://doi.org/10.2196/jmir.2143

Koivumäki, T., Pekkarinen, S., Lappi, M., Väisänen, J., Juntunen, J., \& Pikkarainen, M. (2017). consumer adoption of future MyData-based preventive eHealth services: an acceptance model and survey study. Journal of medical Internet research, 19(12), e429. https://doi.org/10.2196/jmir.7821

Lafky, D. B., \& Horan, T. A. (2011). Personal health records: Consumer attitudes toward privacy and security of their personal health information. Health Informatics Journal, 17(1), 63-71. https://doi.org/10.1177/1460458211399403

Mansour, E. (2017). Health informatics: The ownership and use of mobile medical applications among Egyptian patients. Journal of Librarianship and Information Science, 49(3), 335-355. https://doi.org/10.1177/0961000616637669

Mansour, E. (2018). Egyptian patients' perceptions of using personal health records (PHRs): an exploratory study. Global Knowledge, Memory and Communication, 67(8/9), 523-546. https://doi.org/10.1108/GKMC-04-2018-0034

MCIT. (2019). ICT for Health. [Online] Retrieved from: http://www.mcit.gov.eg/Digital_Government/ICT_for_Health

Najaftorkaman, M. (2016). Facilitators and Barriers to User Adoption of Electronic Health Record Systems (Doctoral dissertation). Griffith University, Gold Coast, Australia.

Noblin, A. M., Wan, T. T., \& Fottler, M. (2012). The impact of health literacy on a patient's decision to adopt a personal health record. Perspectives in Health Information Management/AHIMA, American Health Information Management Association, 9(Fall).

Noblin, A. M., Wan, T. T., \& Fottler, M. (2013). Intention to use a personal health record: a theoretical analysis using the technology acceptance model. International Journal of Healthcare Technology and Management, 14(1-2), 73-89. https://doi.org/10.1504/IJHTM.2013.055085

Norman, C. D., \& Skinner, H. A. (2006). eHEALS: the eHealth literacy scale. Journal of medical Internet research, 8(4), e27. https://doi.org/10.2196/jmir.8.4.e27 
Otte-Trojel, T., de Bont, A., Rundall, T. G., \& van de Klundert, J. (2015). What do we know about developing patient portals? A systematic literature review. Journal of the American Medical Informatics Association, 23(e1), e162-e168. https://doi.org/10.1093/jamia/ocv114

Ozok, A. A., Wu, H., \& Gurses, A. P. (2017). Exploring patients' use intention of personal health record systems: implications for design. International Journal of Human-Computer Interaction, 33(4), 265-279. https://doi.org/10.1080/10447318.2016.1277637

Pagliari, C., Detmer, D., \& Singleton, P. (2007a). Electronic personal health records. Emergence and Implications for the UK. London: The Nuffield Trust. https://doi.org/10.1136/bmj.39279.482963.AD

Pottas, D., \& Mostert-Phipps, N. (2013). Citizens and personal health records-the case of Nelson Mandela Bay. Studies in health technology and informatics, 192, 501-504.

Raisinghani, M. S., \& Young, E. (2008). Personal health records: key adoption issues and implications for management. International Journal of Electronic Healthcare, 4(1), 67-77. https://doi.org/10.1504/IJEH.2008.018921

Randeree, E. (2009). Investigating literacy as a predictor of adoption and usage. In Proceedings of the Southern Association for Information Systems Conference, Charleston, SC (pp. 152-157).

Ratzan, S. C., Parker, R. M., Selden, C. R., \& Zorn, M. (2000). National library of medicine current bibliographies in medicine: health literacy. Bethesda, MD: National Institutes of Health, US Department of Health and Human Services.

Reda, L. (2018, May 30). Analysis: What are Egyptians using the internet for?. Egypt Today. Retrieved from https://www.egypttoday.com/Article/3/50919/Analysis-What-are-Egyptians-using-the-internet-for

Roehrs, A., Da Costa, C. A., da Rosa Righi, R., \& De Oliveira, K. S. F. (2017). Personal health records: a systematic literature review. Journal of medical Internet research, 19(1), e13. https://doi.org/10.2196/jmir.5876

Sarter, N. B., \& Woods, D. D. (1991). Situation awareness: A critical but ill-defined phenomenon. The International Journal of Aviation Psychology, 1(1), 45-57. https://doi.org/10.1207/s15327108ijap0101_4

Showell, C. (2017). Barriers to the use of personal health records by patients: a structured review. PeerJ, 5, e3268. https://doi.org/10.7717/peerj.3268

Statista. (2019). Internet user penetration in Egypt from 2013 to 2019. [Online] Retrieved from https://www.statista.com/statistics/484939/internet-user-reach-egypt/ [Accessed 4 May 2019]

Tang, P. C., Ash, J. S., Bates, D. W., Overhage, J. M., \& Sands, D. Z. (2006). Personal health records: definitions, benefits, and strategies for overcoming barriers to adoption. Journal of the American Medical Informatics Association, 13(2), 121-126. https://doi.org/10.1197/jamia.M2025

Tarver, W. L., \& Haggstrom, D. A. (2019). The Use of Cancer-Specific Patient-Centered Technologies Among Underserved Populations in the United States: Systematic Review. Journal of medical Internet research, 21(4), e10256. https://doi.org/10.2196/10256

Tavares, J., \& Oliveira, T. (2016). Electronic health record patient portal adoption by health care consumers: an acceptance model and survey. Journal of medical Internet research, 18(3), e49. https://doi.org/10.2196/jmir.5069

U.S Department of Health and Human Services. (2008). The nationwide privacy and security framework for electronic exchange of individually identifiable health information. Office of the National Coordinator for Health Information Technology. Retrieved from http://www.healthit.gov/sites/default/files/nationwide-ps-framework-5.pdf

Venkatesh, V., Morris, M. G., Davis, G. B., \& Davis, F. D. (2003). User acceptance of information technology: Toward a unified view. MIS quarterly, 425-478. https://doi.org/10.2307/30036540

Venkatesh, V., Thong, J. Y., \& Xu, X. (2012). Consumer acceptance and use of information technology: extending the unified theory of acceptance and use of technology. MIS quarterly, 36(1), 157-178. https://doi.org/10.2307/41410412

Walsh, L., Hemsley, B., Allan, M., Adams, N., Balandin, S., Georgiou, A., ... Hill, S. (2017). The e-health literacy demands of Australia's My health record: a heuristic evaluation of usability. Perspectives in health information management, 14(Fall).

Warshaw, P. R., \& Davis, F. D. (1985). Disentangling behavioral intention and behavioral expectation. Journal of experimental social psychology, 21(3), 213-228. https://doi.org/10.1016/0022-1031(85)90017-4

WHO-EMRO. (2018). Annual report 2017. World Health Organization. 
Winkelman, W. J., Leonard, K. J., \& Rossos, P. G. (2005). Patient-perceived usefulness of online electronic medical records: employing grounded theory in the development of information and communication technologies for use by patients living with chronic illness. Journal of the American Medical Informatics Association, 12(3), 306-314. https://doi.org/10.1197/jamia.M1712

Worldpopulationreview. (2019). Egypt Population 2019. [Online] Retrieved from http://worldpopulationreview.com/countries/egypt-population/ [Accessed 4 May 2019].

$\mathrm{Wu}, \mathrm{H}$. (2013). Exploring healthcare consumer acceptance of personal health information management technology through personal health record systems (Doctoral dissertation). University of Maryland, Baltimore County, USA.

Wynia, M., \& Dunn, K. (2010). Dreams and nightmares: practical and ethical issues for patients and physicians using personal health records. The Journal of Law, Medicine \& Ethics, 38(1), 64-73. https://doi.org/10.1111/j.1748-720X.2010.00467.x

Yuan, S., Ma, W., Kanthawala, S., \& Peng, W. (2015). Keep using my health apps: Discover users' perception of health and fitness apps with the UTAUT2 model. Telemedicine and e-Health, 21(9), 735-741. https://doi.org/10.1089/tmj.2014.0148

\section{Copyrights}

Copyright for this article is retained by the author(s), with first publication rights granted to the journal.

This is an open-access article distributed under the terms and conditions of the Creative Commons Attribution license which permits unrestricted use, distribution, and reproduction in any medium, provided the original work is properly cited. 